\title{
Knowledge Transferring Features in Traditional Construction Project Team in China: Based on SNA
}

\author{
Yong Tang ${ }^{1,2}$ \\ ${ }^{1}$ Business School, Central South University, Changsha, China \\ ${ }^{2}$ Urban Management Department, Hunan City University, Yiyang, China \\ Email: tyzyhtt@126.com
}

Received June 26, 2012; revised July 26, 2012; accepted August 4, 2012

\begin{abstract}
For the uniqueness and one-time feature, construction project is urgently needed in knowledge transferring to acquire its high performance. This paper focuses in the exploration of knowledge transferring features from the network perspective. Based on the data from a real construction project team of 40 members, we find that all members have knowledge transferring behavior, while the knowledge transferring density is comparatively low and distance is long; from cluster analysis we find that 89 different clusters in the whole network, and some members (especially the managers) repeated appear in different clusters and assume the responsibilities in coordinating knowledge transferring.
\end{abstract}

Keywords: Knowledge Transferring; Construction Project; Social Network Analysis; Cluster

\section{Introduction}

Transferring knowledge effectively is long been viewed as an important indicator for a company to acquire competence advantage (Linda Argotea, 2000) [1]. In practical circles, knowledge transferring can be achieved through transfer of best practices (Szulanski, 1996) [2], new product development (Hansen, 1999) [3] or learning rates (Darr et al., 1995) [4]. In academic circles, scholars consistently deem knowledge transferring abilities as an effective means to improve company's performance (Kogut et al., 1992) [5]. In knowledge-based era, organizations are viewed as social communities specializing in efficient knowledge creation and transfer (Kogut et al., 1996) [6].

While most of previous researches take high-growth enterprises as their research objectives, seldom touching some traditional while less-developed companies (Craig Mittonn et al., 2007) [7]. Even for knowledge management in project, scholars pay too much attention on some R\&D or software projects (Stanisław Gasik, 2011) [8], which are very different in terms of management style and organizational structure (Mian Ajmal et al., 2010) [9].

SNA (Social Network Analysis) is a widely used method in describing group characteristics concerning with social communication. According social network, the individuals who have connections can be grouped into a whole network, and each one is called as node in the network. So, SNA is a method in calculating some variables such as network density, cohesion degree based on ties and related weights of every pair of ties (Wasserman, 1994) [10]. So it is efficient in telling the features of group communication and the individual communication in the group.

\section{The Knowledge Management in Construction Project Team}

Construction company is a very special kind of body in industrial circle. It exists for a long time, and the operation style and management mode are very different. Because construction projects are site-specific, the workers are needed to leave their companies to stay at the work site. So, every new project will call for new form of project team, as well as new management style. Because project is one-time matter, related project team is also temporary. Members cannot form deep relations during their work period for short-time touch, and most of members can not even know others well before the project comes to the end of life cycle. While new project needs new working style and management ideas. Members working for the project need to learn to be adapt to new environment and new co-workers, and new commands and indications are transferred from one group to the others in order to smooth the management processes. So, knowledge, which is symbolized by tacit or implicit forms, will be transferred from one to the other among network, and related transferring effectiveness sometimes determines the final performance of this project management (Ray Reagans et al., 2003) [11]. 
Under China's construction management system, a typical construction project team is generally formed by two individuals: one belongs to the first-tier contactor, usually from a contracted company; the others are called subcontractors, whose major features are informal organizational structure or legal identity and less capable in dealing with whole issues happening in construction processes.

Because most responsibilities are in charge by first-tier contractor, it assumes the whole management jobs and then decides to select the subcontractors. For the on-site work scenario, the first-tire contractor and second-tire contractors often work together to solve the knowledge problems simultaneously. So, for the natural separation of legal position, information communication is not smoothly happening among these two parties. Furthermore, the first-tire, for their excellent performance in related industries, commonly has higher technique advantage when comparing with second-tire contractors, especially under China's context.

For the owners, the separation of contractors is not good for their management and supervision, but in order to acquire comparative advantages and achieve cost saving in construction processes, the owner from anther side is motivated to permit the existence of multi-tire contractors. In order to efficiently manage project, owners and first-tire contractors expect to reduce tedious management cost and focus on confined scope, therefore, better analysis the management scope and refine the management targets is necessary.

Because knowledge is means for different parties' communication, the refinery of knowledge transferring structure is actually optimizing the management scope. Though there are some literatures on knowledge transferring research (Nicholas Berente, 2010) [12], few regards knowledge transferring happens in a whole network, therefore cannot fully describe the transferring structure for construction project. This paper is mainly focused on the knowledge transferring channels in a given project team. With the aid of social network analysis, this paper expects to draw up basic features of knowledge transferring in project team.

\section{Case Study}

\subsection{Background}

Luhongshi Major Bridge Construction Project belongs to the key project of Luiyang-Zhangjiang railway, which is located in Luhongshi town of Yongzhou, Hunan Province. The project has the length of $2600 \mathrm{~m}$, and total cost estimation is more than 200 million RMB. In 2006, this project is contracted to a construction company from China Railway Ministry. With the authorization, the project team of 10 members is fully in charge of the contract management and 2 subcontracts have been signed to assist the labor forces requirement with the permission of owner. The subcontracts are from 2 groups: one is from Jiujiang, Jiangxi province, and it has 16 labors; the other group, which has 14 persons, is from Fuqing, Fujian province. So, the whole project team has 40 members from 3 different groups.

\subsection{Case Study Processes}

In order to fully describe the knowledge transferring state, case study confirms to the requirement of whole network analysis:

- To define the board line of whole network;

- To refine the questionnaire according to related research;

- To analyze the network features based on data;

- To explain the connation of results.

\subsection{Detailed Processes}

- The definition of board line

Project team is the body fully in charge of the project management, so it can be regarded as a whole network in which team members communicate and knowledge transfers along the member network (Wasserman, 1994) [10]. In this case, 3 groups, i.e., the first-tire contractor and 2 labor force subcontractors are gathering into the whole network.

- Date collection

Because it is only concerning with knowledge, all forms of knowledge such as indications, paperwork information, guidance, orders, notices, is considered. According to knowledge transferring rules, any two nodes can be viewed as knowledge transferring tie as long as any form of knowledge flows between them. So, the questionnaire is designed as Table 1. For only 40 members in 3 groups, we can conveniently get all questionnaires with the assistance of project manager.

Table 1. The questionnaire of knowledge transferring whole network.

- Basic information:

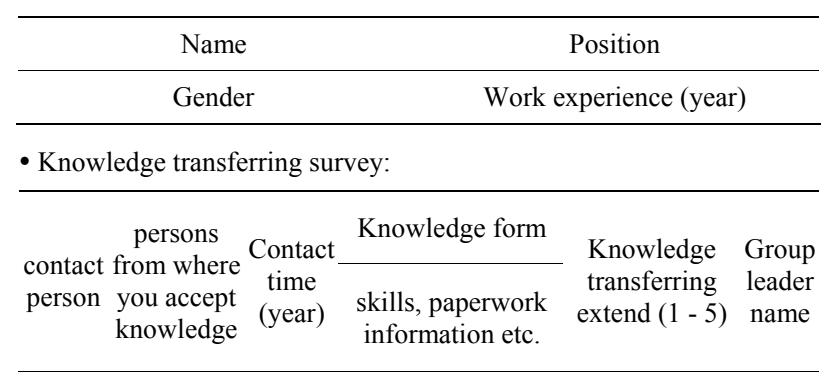


- Data analysis

Step 1: network description

With the questionnaire in Table 1, we get 40 nodes and related relations illustrated in Figure 1. According to Figure 1, we can easily find that node 9, node 20 and node 35 have dense in (out) ties with other nodes, which means they have more opportunities to transfer knowledge than others. Actually, the nodes above are managers for 3 groups. While some nodes such as node 25, node 26 , node 14 etc. have very sparse ties with others, indicating they have few channels to transfer knowledge. When tracing the nodes to real position, we find that they are freshmen and apprentices in 3 groups, and they only communicate with their overmen. From Figure 2 we can also draw the conclusion that knowledge transferring level in contractor team is higher than subcontractors.

Table 2 shows that in this whole network, whole destiny is at a low level, and average distance is comparative big with the consideration of network size. It reflects knowledge transferring in construction project whole network is not so effective. Bigger distance means high cost of knowledge transferring. In a comparative agglomerated worksite, it is not good for team cooperation and freshmen growth.

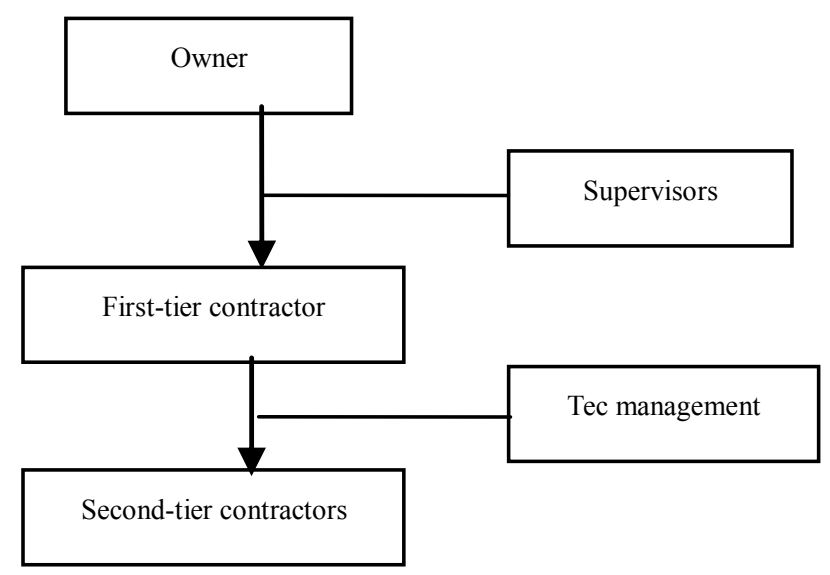

Figure 1. Construction project team structure.

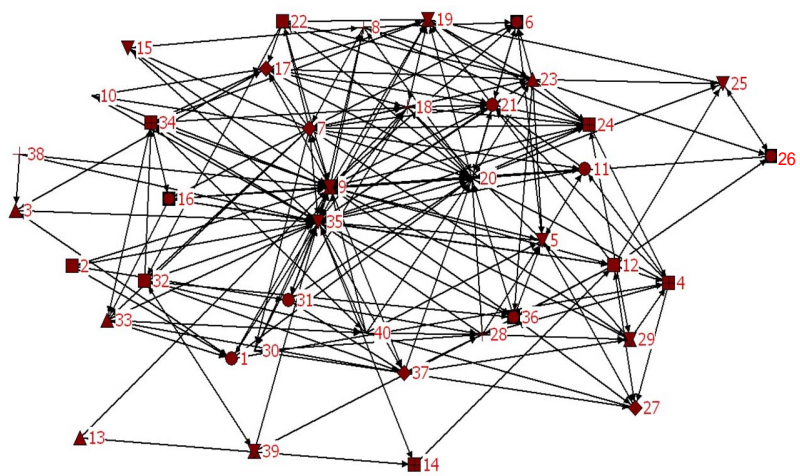

Figure 2. Knowledge transferring network of the project team.
Table 2. Descriptive statistics of whole network.

\begin{tabular}{ccc}
\hline Number & Item & Value \\
\hline 1 & Density & 0.1641 \\
2 & Standard deviation & 0.3704 \\
3 & Average distance & 2.135 \\
4 & Distance-based cohesion & 0.534 \\
\hline
\end{tabular}

Step 2: cluster analysis

Step 1 tells us the whole structure of knowledge transferring. It pessimistically predicts the unsatisfaction of this team work. Social network theory tells us that whole structure is based on whole information of the network, so it has not explained the detailed information of inner situation, and it is inefficient in explaining the features of knowledge transferring. In order to find out the knowledge transferring mechanism, we take cluster analysis which can clearly divide a whole network into some small groups. In each group the information flows according to a comparatively stable rule, and every node in the group is interconnected. In SNA, each group is called as a cluster. So, the second step is to explore the clusters in whole network, in order to find out how many clusters which representing same knowledge transferring features are found.

With further analysis, we can get as many as 89 clusters (Table 3). According to Newman (2004) [13], cluster is a subgroup which is more stable, target-oriented and easily communicated. In each cluster, knowledge is more easily transferred comparing with others. In other words, though we can easily define the board line of whole network, knowledge transferring is not happening in the whole project team. Most of knowledge transferring happens only in small groups as clusters.

In the 89 clusters, some members appear in several clusters. So, we can easily draw the clusters diagram illustrated in Figure 3. The more left means more clusters participation. So, note 35 and note 9 are at the highest level of cluster joining, while node 13 only joins one cluster. According to SNA, high level of participation of cluster means higher knowledge transferring level, so, we can easily conclude that node 35 and node 9 are major transferring nodes in the network.

Figure 4 is the overlap matrix, which illustrates the co-membership in the whole network. Co-membership is the ones who should the responsibility of maintain several clusters' structure and feature. So, if higher comembership qualification means he is at the key position of maintaining many clusters. We can get the same conclusion as in Figure 2 that node 35 and node 9, which have 27 ties in the whole network, assumes biggest responsibilities in transferring knowledge. 
Table 3. Cluster analysis.

\begin{tabular}{|c|c|c|c|c|c|}
\hline $\mathrm{N}$ & Cluster & $\mathrm{N}$ & Cluster & $\mathrm{N}$ & Cluster \\
\hline 1 & 791820212435 & 31 & 7182021232435 & 61 & 42429 \\
\hline 2 & 789202435 & 321 & 18192021232435 & 62 & 678920 \\
\hline 3 & 79162035 & 33 & 7820232435 & 63 & 6792021 \\
\hline 4 & 9181920212435 & 34 & 20233536 & 64 & 67202123 \\
\hline 5 & 918203135 & 35 & 5182335 & 65 & 6782023 \\
\hline 6 & 920313537 & 36 & 5233536 & 66 & 569 \\
\hline 7 & 192035 & 37 & 2028313537 & 67 & 5623 \\
\hline 8 & 9203536 & 38 & 20283540 & 68 & 7917182021 \\
\hline 9 & 9203540 & 39 & 5283540 & 69 & 7917202122 \\
\hline 10 & 293135 & 40 & 122835 & 70 & 791017 \\
\hline 11 & 12935 & 41 & 28303537 & 71 & 91718192021 \\
\hline 12 & 791035 & 42 & 283539 & 72 & 917181934 \\
\hline 13 & 79112135 & 43 & 32343540 & 73 & 91719202122 \\
\hline 14 & 591135 & 44 & 73235 & 741 & 171819202123 \\
\hline 15 & 9121635 & 45 & 323536 & 75 & 71718202123 \\
\hline 16 & 9122135 & 46 & 323537 & 761 & 171920212223 \\
\hline 17 & 9123536 & 47 & 323539 & 77 & 71720212223 \\
\hline 18 & 7891535 & 48 & 7163335 & 78 & 72232 \\
\hline 19 & 591835 & 49 & 16333435 & 79 & 19202325 \\
\hline 20 & 593536 & 50 & 13335 & 80 & 20232526 \\
\hline 21 & 593540 & 51 & 333537 & 81 & 122526 \\
\hline 22 & 793035 & 52 & 33343540 & 82 & 52736 \\
\hline 23 & 9303537 & 53 & 4202124 & 83 & 52740 \\
\hline 24 & 918193435 & 54 & 42028 & 84 & 122736 \\
\hline 25 & 9163435 & 55 & 1420 & 85 & 792429 \\
\hline 26 & 9343540 & 56 & 41221 & 86 & 5929 \\
\hline 27 & 93538 & 57 & 41227 & 87 & 92937 \\
\hline 28 & 1335 & 58 & 41228 & 88 & 52829 \\
\hline 29 & 33538 & 59 & 41121 & 89 & 282937 \\
\hline 30 & 121435 & 60 & 42829 & & \\
\hline
\end{tabular}

\section{Discussion and Analysis}

For the uniqueness and one-time feature, construction project is urgently needed in knowledge transferring to acquire its high performance. While in reality, for the traditional management style, construction project management has long ignored knowledge management. As one key function of knowledge management, the effectiveness of knowledge transferring, no matter its mechanism or its channels, attracts little attention both in academic circle and practical circle. This paper focuses in the exploration of knowledge transferring features using case study.

At first, this paper designs the questionnaire according to knowledge transferring channel. Because project team is confined to a definite scope, it is easily to confirm the whole network's board. We choose a case in reality and make 40 members (which is also the whole worker group in a major bridge construction project) as the nodes of a whole network.

Then, we collect the data mainly on knowledge transferring ties. Each member in the whole network is asked to list no more 10 members with whom knowledge transferring happens. We find that all members have knowledge transferring behavior (no matter input or output knowledge), which proves even in traditional industry, knowledge transferring happen on even single person.

Third, we do analysis of data with SNA method.

We find that in the whole network, density is comparatively low and distance is long, illustrating the knowledge transferring behavior is not frequent as in other industries, which further testify the conclusion of traditional industry's sluggish knowledge management passion.

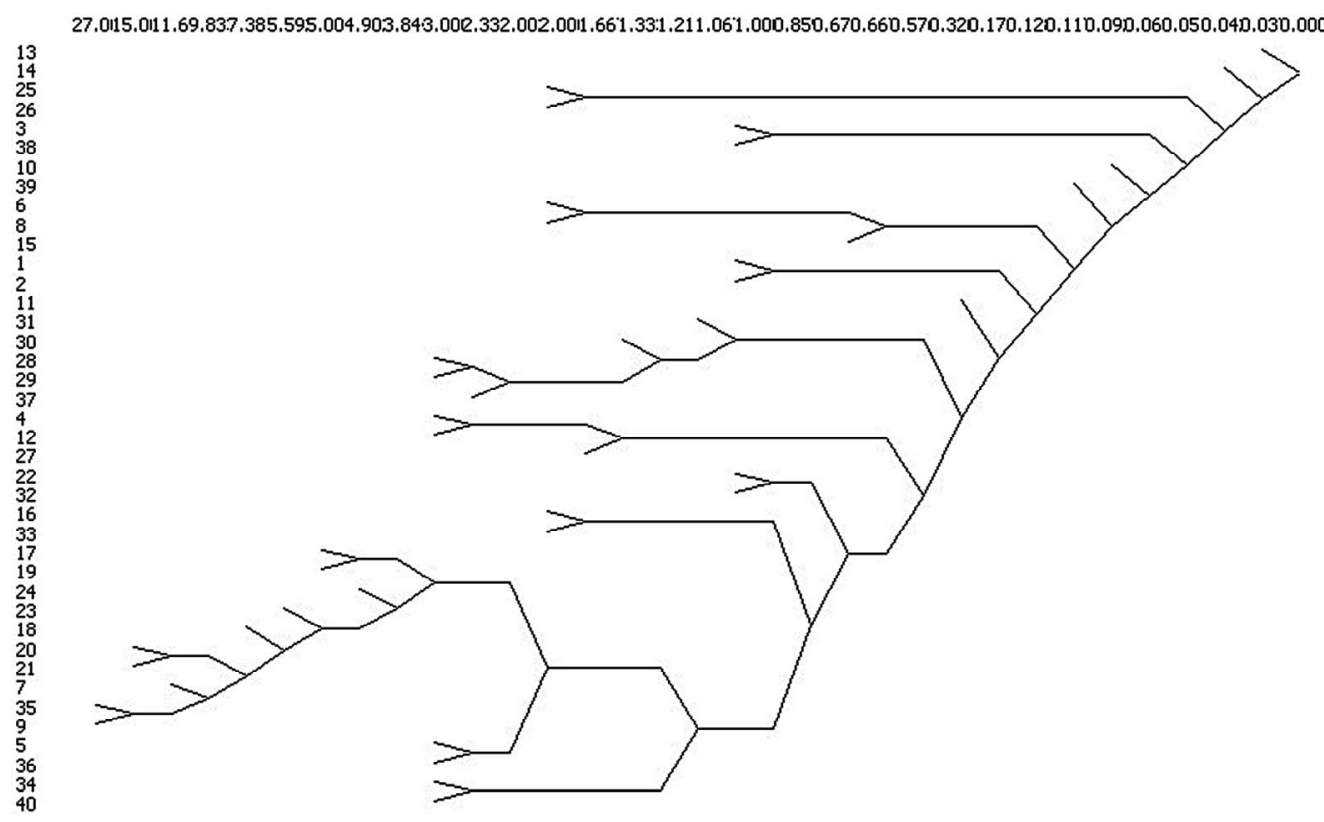

Figure 3. Cluster diagram. 


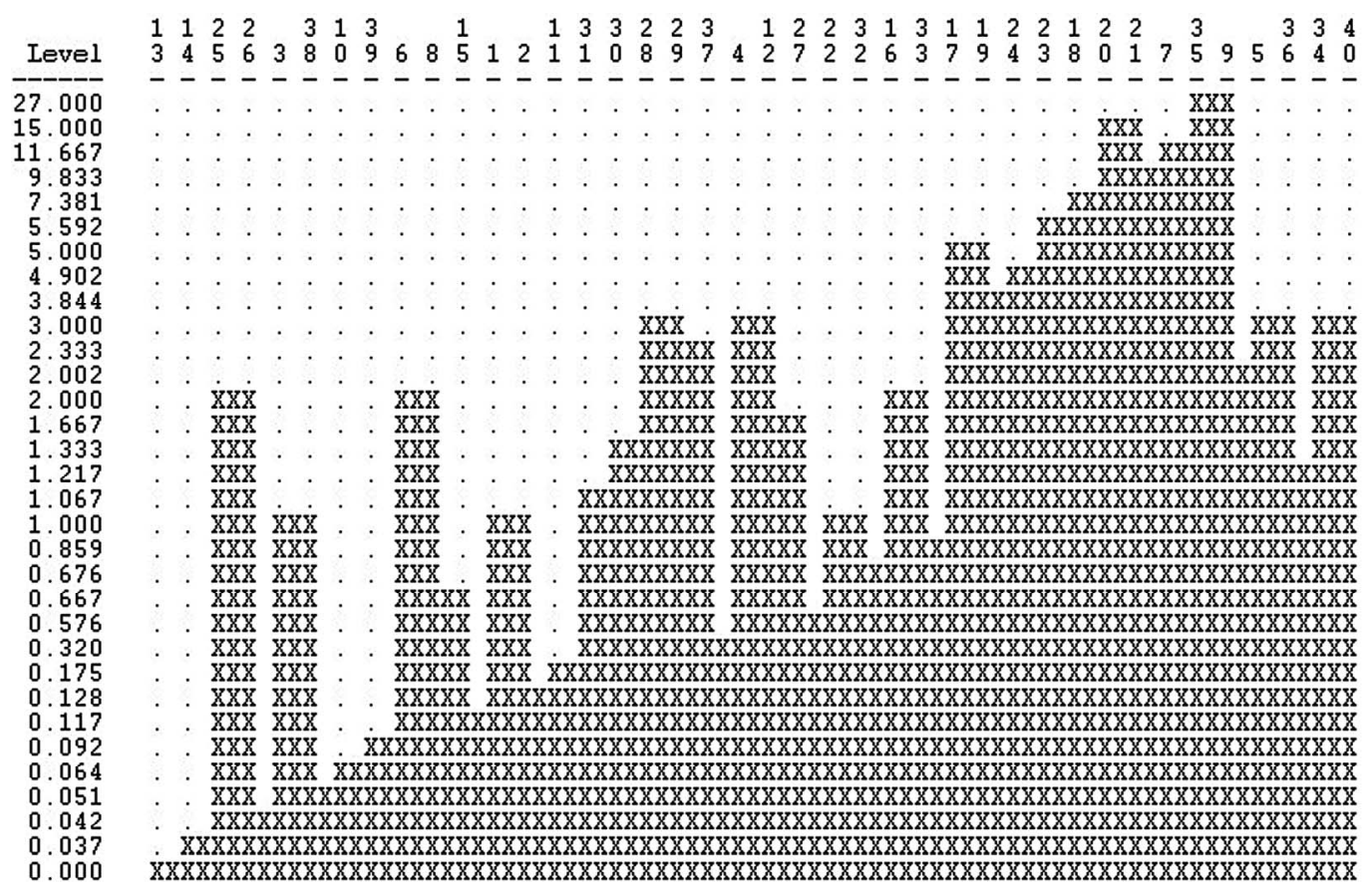

Figure 4. Hierarchical clustering of overlap matrix.

We then calculate the clusters in whole network, and get 89 different clusters in the whole network. For the variation of clusters, we can easily conclude that even in a highly compacted team, small groups appear in great number. This can be explained from two facets: one, the highly divisional working structure makes knowledge separated from one division to another. Different divisions have natural handicaps in communication; two, the team is not well designed in communication, members choose to communicate only in a very small scope. This organization design seriously handicaps the knowledge transferring effectiveness.

Based on clusters analysis, we further search for "bridge" in knowledge transferring. With the aid of cluster diagram, it is easy to find that some members repeated appear in different clusters and assume the responsibilities in coordinating knowledge transferring. In co-membership analysis, we get the same result.

As for the reasons, we can do analysis as below:

As for low density and long distance, the first reason is weak ties between members. Because most members of construction project are randomly selected, they get little opportunity to know more people in a short time [14]. So most time they will only communicate with the members if necessary. The second reason is the rank difference in members. As Figure 2 shows, the cluster has the feature that most of members belong to the same rank (such as employees in a company or migrant workers). The rank gap handicaps more communication, so some other factors such as work requirement, habit identity, dominates the ties.
As for high co-membership, we find that some nodes are occupying the major position in coordinating the whole network. Node 9 and node 35 are managers of subcontractors, and nodes 20, 21 are the persons in charge of contractor. They not only need to transfer knowledge to subordinates, but also to collect knowledge from other groups so as to better make decisions. In Chinese traditional project management system, the responsibility system requires managers fully responsible for the success or failure. So, they are encouraged or forced to communicate with others to the biggest extend. And we can also see many nodes have no impetus to absorb or release knowledge, and most of them are apprentices or migrant workers. Because in China's bureaucracy, the less ranked are only needed to follow the indicators, they will give up their initiatives in learning or communication.

\section{Conclusions and Recommendations}

Knowledge transferring is very important in team management, for it is simultaneously efficient in guiding newest information and guidance to the team members, as well as enhancing the competitiveness. However, traditional construction team, though stable in the structure, is seldom studied in its knowledge perspective. Facing with instable construction circumstance, the team is required to response as quickly as possible to take actions. So, the speed of knowledge transferring and the effectiveness of it are needed. In order to explore the features of knowledge transferring in traditional construction 
team, this paper thinks the information which shared by members or transferred between members is knowledge. For whole team in implementing construction project, there are generally some groups such as the contractor and subcontractors, and information (or knowledge) transferring in the groups are not the same. Taking the construction team as a whole network, and adopting SNA, this paper calculates some network variables which depict the features of knowledge transferring in construction team. From the variables, we can see that the knowledge transferring is not in the same extend between different members, and some members can be categorized into a same cluster. And the transferring difference is very obvious between contractor group and subcontractor group.

On the base of knowledge transferring behavior, we think related results cannot guarantee the sustainable development for teams in construction companies because knowledge transferring is so useful for economic growth. As for suggestions: Firstly, the construction project members should strengthen expertise training, reducing the number of migrant workers or improving the identity recognition, so as to make all members equal in their identity; Secondly, the managers should authorize more to subordinates, makes them assume more responsibilities, so as to motivate more members participating in project; And last, China's construction project should introduce more innovation elements, elevating knowledge level and make more people explore the operational modes.

\section{Acknowledgements}

The project is supported by the Hunan City Economy Research Base and Hunan Urbanization Research Base.

\section{REFERENCES}

[1] L. Argotea and P. Ingramb, "Knowledge Transfer: A Basis for Competitive Advantage in Firms," Organizational Behavior and Human Decision Processes, Vol. 82, No. 1, 2000, pp. 150-169. doi:10.1006/obhd.2000.2893

[2] G. Szulanski, "Exploring Internal Stickiness: Impediments to the Transfer of Best Practice within the Firm," Journal of Strategic Management, Vol. 17, 1996, pp. 27-43.

[3] M. T. Hansen, "The Search-Transfer Problem: The Role of Weak Ties in Sharing Knowledge across Organization Subunits," Administrative Science Quarterly, Vol. 44, No.

\section{1, 1999, pp. 82-111. doi:10.2307/2667032}

[4] E. Darr, L. Argote and D. Epple, "The Acquisition, Transfer and Depreciation of Knowledge in Service Organizations: Productivity in Franchises," Management Science, Vol. 41, No. 11, 1995, pp. 1750-1762. doi: $10.1287 / \mathrm{mnsc} .41 .11 .1750$

[5] B. Kogut and U. Zander, "Knowledge in the Firm, Combinative Capabilities and the Replication of Technology," Organization Science, Vol. 3, No. 3, 1992, pp. 383-397. doi:10.1287/orsc.3.3.383

[6] B. Kogut and U. Zander, "What Firms Do? Coordination, Identity and Learning," Organization Science, Vol. 7, No. 5, 1996, pp. 502-518. doi:10.1287/orsc.7.5.502

[7] C. Mittonn, et al., "Knowledge Transfer and Exchange: Review and Synthesis of the Literature," Milbank Quarterly, Vol. 85, No. 4, 2007, pp. 729-768. doi:10.1111/j.1468-0009.2007.00506.x

[8] S. Gasik, "A Model of Project Knowledge Management," Project Management Journal, Vol. 42, No. 3, 2011, pp. 23-44. doi:10.1002/pmj.20239

[9] M. Ajmal, P. Helo and T. Kekäle, "Critical Factors for Knowledge Management in Project Business," Journal of Knowledge Management, Vol. 14, No. 1, 2010, pp. 156168. doi:10.1108/13673271011015633

[10] S. Wasserman and K. Faust, "Social Networks Analysis: Methods and Applications," Cambridge University Press, Cambridge, 1994, p. 20. doi:10.1017/CBO9780511815478

[11] R. Reagans and B. McEvily, "Source Network Structure and Knowledge Transfer: The Effects of Cohesion and Range," Administrative Science Quarterly, Vol. 48, No. 2, 2003, pp. 240-267. doi:10.2307/3556658

[12] N. Berente, R. Baxter and K. Lyytinen, "Dynamics of Inter-Organizational Knowledge Creation and Information Technology Use across Object Worlds: The Case of an Innovative Construction Project," Construction Management and Economics, Vol. 28, No. 6, 2010, pp. 569588. doi:10.1080/01446193.2010.489926

[13] M. E. J. Newman, "Detecting Community Structure in Networks," The European Physical Journal B, Vol. 38, No. 2, 2004, pp. 321-330. doi:10.1140/epjb/e2004-00124-y

[14] P. S. W. Fong and S. K. Y. Choi, "The Processes of Knowledge Management in Professional Services Firms in the Construction Industry: A Critical Assessment of both Theory and Practice," Journal of Knowledge Management, Vol. 13, No. 2, 2009, pp. 110-126. doi: $10.1108 / 13673270910942736$ 